\title{
Mineralogical Composition of Urinary Stones and Their Frequency in Patients: Relationship to Gender and Age
}

\author{
Behnam Keshavarzi ${ }^{1}$, Nasrin Yavar Ashayeri ${ }^{1, *}$, Farid Moore ${ }^{1}$, Dariush Irani ${ }^{2}$, Sina Asadi ${ }^{1}$, \\ Alireza Zarasvandi ${ }^{3}$ and Mehrdad Salari ${ }^{4}$ \\ 1 Department of Earth Sciences, College of Sciences, Shiraz University, Shiraz 71454, Iran; \\ bkeshavarzi@shirazu.ac.ir (B.K.); moore@susc.ac.ir (F.M.); sinaasad@sirazu.ac.ir (S.A.) \\ 2 Department of Urology and Endourology, Shahid Faghihi Hospital, Shiraz University of Medical Sciences, \\ Zand Street, P.O. Box 71344, Shiraz, Iran; iranidar@gmail.com \\ 3 Department of Geology, Shahid Chamran University (SCU), Ahvaz 87234, Iran; zarasvandi_a@scu.ac.ir \\ 4 Department of Anesthesia, Shaheed Faghihi Hospital, Shiraz University of Medical Sciences, Zand Street, \\ P.O. Box 71344, Shiraz, Iran; salari.mehrdad@gmail.com \\ * Correspondence: nasrinyavar@shirazu.ac.ir; Fax: +98-713-228-4572
}

Academic Editor: Paul Sylvester

Received: 16 October 2016; Accepted: 9 December 2016; Published: 14 December 2016

\begin{abstract}
This investigation reports the mineralogy and possible pathological significance of urinary stones removed from patients in Fars province, Iran. X-ray diffraction (XRD), scanning electron microscopy (SEM) and polarizing microscope (PM) techniques were used to investigate the mineralogical compositions of urinary stones. The identified mineral components include whewellite, weddellite, hydroxyapatite, uricite and cystine. These techniques revealed that the whewellite and uricite were the most common mineral phases. Platy-like/monoclinic whewellite, prismatic/monoclinic uric acid and hexagonal cystine crystals were revealed by SEM. Biominerals (calcium carbonate) and quartz were also identified in PM images. Of the variables determining the type of precipitated minerals, the effects of $\mathrm{pH}$ on depositional conditions proved to be the most apparent parameter, as shown by occurrences and relationships among the studied minerals. Our results revealed the importance of detailed knowledge of mineralogical composition in assessing the effects of age and sex. The highest incidence of urinary stones was observed in the 40-60 age group. Calcium oxalate and uric acid stones are more frequent in men than women. Finally, the study concluded that knowledge of the mineralogical composition of urinary stones is important as it helps the scientific community to explain the chemistry and the etiology of the calculi in the urinary system.
\end{abstract}

Keywords: mineralogy; urinary stone; XRD and SEM; gender and age; Fars

\section{Introduction}

It is important to stress that physico-chemical principles fundamentally control the complex interactions of solutions, biomolecules, and minerals in the realms of the human body as well as in the natural geological environment [1]. Urinary stones are products of the pathological biomineralization processes in the urinary system [2]. The composition of urinary stones comprises two parts. The first part is an organic matrix containing mainly proteins, lipids, carbohydrates, and cellular components. The other part is the biomineral component [3].

Urinary stones are typically classified by their location in the kidney, urethra, and bladder. Kidney stones are hard, rock-like crystals of varying sizes and shapes. They occur when salts in the urine precipitate and form solid materials [4]. About 40 components have been identified to form urinary calculi. The most common urinary stone types are calcium oxalates, magnesium and calcium 
phosphates, uric acid and their combinations [5]. The most frequent components are the calcium oxalates, whewellite and weddellite, as monohydrate $\left(\mathrm{CaC}_{2} \mathrm{O}_{4} \cdot \mathrm{H}_{2} \mathrm{O}\right)$ and dihydrate $\left(\mathrm{CaC}_{2} \mathrm{O}_{4} \cdot 2 \mathrm{H}_{2} \mathrm{O}\right)$. The occurrence frequency of whewellite is $78 \%$ and that of weddellite is $43 \%$ [6]. In addition to calcium oxalate, other calcium ( $\mathrm{Ca}$ ) compounds are also present in human urinary stones: calcium phosphate $\left[\mathrm{Ca}_{10}\left(\mathrm{PO}_{4}\right)_{6} \cdot 2 \mathrm{H}_{2} \mathrm{O}\right]$, calcium carbonate $\left(\mathrm{CaCO}_{3}\right)$, brushite $\left(\mathrm{CaHPO}_{4} \cdot 2 \mathrm{H}_{2} \mathrm{O}\right)$, gypsum $\left(\mathrm{CaSO}_{4} \cdot 2 \mathrm{H}_{2} \mathrm{O}\right)$, and dolomite $\left[\mathrm{CaMg}\left(\mathrm{CO}_{3}\right)_{2}\right]$ [7]. On the basis of major constituents, other types of kidney stones include magnesium ammonium phosphate $\left(\mathrm{MgNH}_{4} \cdot \mathrm{PO}_{4} \cdot 6 \mathrm{H}_{2} \mathrm{O}\right)$ or struvite stones, uric acid $\left(\mathrm{C}_{5} \mathrm{H}_{4} \mathrm{~N}_{4} \mathrm{O}_{3}\right)$ stones, and cysteine $\left(\mathrm{C}_{6} \mathrm{H}_{12} \mathrm{~N}_{2} \mathrm{O}_{4} \mathrm{~S}_{2}\right)$ stones, but the percentages of these stones are $15 \%, 5 \%-10 \%$, and $1 \%$, respectively of the total kidney stones [8]. Struvite stones are commonly associated with urinary tract infections. Uric acid stones, associated with hyperuricosuric patients, are found in patients with gout, dehydration, and excessive purine intake. Finally, cystine stones are a rare form associated with inborn errors of metabolism resulting in abnormal absorption of dibasic amino acids in the small bowel and proximal renal tubule $[9,10]$. Most human stones contain more than one crystalline component and hence are termed multicomponent stones. The presence of multicomponent stones suggests multiple physiological conditions that must be unraveled in the process of defining the optimal medical management and the avoidance of stone recurrence [11].

Two separate groups of epidemiological factors are involved in the formation of urinary calculi:

1. Intrinsic factors: sex, age, ethnic, racial and familial background and inherited physiological or anatomical predisposition to urinary calculi.

2. Extrinsic factors: climate, hardness of water available for drinking, the presence or absence of trace elements, differences in occupation, dietary and lifestyle factors [12,13].

The process of stone formation depends on urinary volume; concentrations of calcium, phosphate, oxalate, sodium, and uric acid ions; concentrations of natural calculus inhibitors (e.g., citrate, magnesium); and urinary $\mathrm{pH}$ [14].

Because of the increased incidence of various diseases caused by abnormal mineral deposition, the aetiopathogenesis of diseases caused by pathogenic minerals has gained considerable research attention $[15,16]$. Many theories and studies have attempted to clarify the mechanisms of formation and growth of calculi or stones. However, no satisfactory explanation has yet been put forward, and several questions remain unanswered [17]. Accurate knowledge of the composition of the stone is critical to elucidating the underlying etiology of the clinical disorder(s) that precipitated the stone disease [11]. Early studies on urinary stones have revealed some information on composition, mineralogy, structure, processes of formation and geo-environmental factors [18]. Therefore, accurate analysis of urinary stone composition is a key factor in choosing the most appropriate medical management [19].

In certain areas of the world, including the Middle East which is part of the Afro-Asian stone belt, a high incidence rate of urolithiasis is reported [20]. The Fars province of Iran (SW Iran) is located in this belt. The Fars province has high numbers of cases of urinary stones in the human population. Given this context, urinary stones can be studied by investigating their mineralogy from a medical geology viewpoint. As there were no data on the mineralogical composition of urinary stones of the Fars province population in Iran, this primary study focuses on the quantitative phase analysis and morphological characterization of constituent phases in urinary stones using the Rietveld-based refinement technique with powder X-ray diffraction (PXRD) data and scanning electron microscopy (SEM), respectively. We also interpret these data to determine the relationship between age and sex and the frequency of urinary stones in view of their mineral composition. The principles of methodology used for such analyses have also been discussed.

\section{Experimental}

\subsection{Samples}

Thirty-nine urinary stone samples were collected between April 2013 and August 2013 from patients undergoing surgery for the PCNL (percutaneous nephrolithotomy) procedure at Shahid 
Faghihi Hospital, Shiraz City. The removed stones were placed in polyethylene dry bottles and kept cool until analysis. All polyethylene bottles were labeled with the name, sex and age of the patient and the date of surgery. The types of urinary stones that were collected were 36 renal, 2 bladders, and 1 ureteral stone samples. Because gender and age are likely factors of urinary stones, they were considered during the sample collection. The patients were 25 males and 14 females ranging in age between 24 and 82 years.

\subsection{Analytical Procedures}

The urinary stone samples were washed in distilled water, dried at ambient temperature and homogenized in agate mortar. The samples mounted into a cavity of the zero background holder silicon ( $25 \mathrm{~mm}$ wide flat plates). In the present study, we attempted to reduce the preferred orientation of particles during sample preparation. Powder of the sample was gently pressed into the holder with the sharp edge of a sheet of glass. Some additional powder was tapped through a sieve onto the holder. Because the grains have a more or less random orientation when falling from the sieve, a surface without very strong preferred orientation of the particles was nearly obtained. The X-ray diffraction (XRD) data were collected using a PW3040 Philips Diffractometer (PANalytical, Amsterdam, The Netherland), which operated at $40 \mathrm{kV}$ and $30 \mathrm{~mA}$ with a nickel-filtered $\mathrm{Cu}-\mathrm{K} \alpha$ at room temperature. The measurements were performed in reflection geometry. The $2 \theta$ scan range was from $10^{\circ}$ to $60^{\circ}$, with a step size of $0.02^{\circ}$ and a counting time of $1 \mathrm{~s}$. Phase identifications were conducted using the X-powder software (version 2010.01.45 PRO; Martin-Islán, Granada, Spain), supported by the Powder Diffraction File (PDF) database of the International Centre for Diffraction Data (ICDD). The quantitative X-ray diffraction (QXRD) analysis was carried out with PROFEX software (version 3.10.2; Döbelin and Kleeberg, Bettlach, Switzerland) [21] and the Rietveld refinement kernel BGMN (version 4.2.22, Netherlands Energy Research Foundation ECN, Rietveld, Petten, The Netherlands) [22]. The X-ray powder profile-fitting structure refinement by the Rietveld method is uniquely versatile for quantitative phase analysis in a multi-phase mixture of polycrystalline materials. This method can be applied successfully for estimating the quantitative abundance of mineral phases in urinary stones. To facilitate a systematic understanding of urinary stones mineralogy, QXRD techniques were used to further examine the changes of phase composition. To evaluate the reliability of the quantitative results from XRD data, the weighted-profile factor $\left(R_{w p}\right)$, expected $R$-factor $\left(R_{\text {exp }}\right)$ and goodness fit factor $\left(X^{2}\right)$ are monitored. The Rietveld based methods are important when attempting to elucidate the mechanism for in vivo crystal growth of urinary stones [23]. It is, however, necessary to emphasize that quantitative phase analysis of urinary stones using the Rietveld method is not straightforward due to the fact that most of the stone samples are crystallographically heterogeneous and the majority of phases present in the urinary stones have low crystal symmetry (triclinic and monoclinic), which in turn leads to a considerable overlapping of peaks in the X-ray powder diffraction pattern [23].

Furthermore, fourteen samples were studied by polarizing microscopy (PM, Olympus, Ramsey, NJ, USA), to identify the optical properties and mineralogical compositions of the studied urinary stones at Shiraz University. In addition, samples with a known composition based on X-ray diffraction (calcium oxalate, cystine, and uric acid stones) were selected for further investigation by scanning electron microscope. Scanning electron microscope (SEM; Leo 1455 VP, Carl Zeiss Ultra Plus, Cambridge, UK) in the central Lab of Shahid Chamran University, Ahvaz, Iran was used to identify the morphology and crystal form of urinary stones.

\section{Results and Discussion}

\subsection{Mineralogy}

The QXRD method is demonstrably capable of providing accurate determinations of individual crystalline phases in urinary stones [21]. For an accurate quantitative analysis of constituent phases in urinary stones it is necessary to perform the Rietveld refinement using high quality X-ray powder 
diffraction data. During the Rietveld refinement, structure parameters, scale factor, unit cell parameters and background coefficients, along with the profile parameters describing the peak shapes and widths are varied through a least-squares procedure until the calculated powder pattern best matches the observed pattern. In order to get an improvement on the calculi phase analysis, a Rietveld refinement of 39 urinary stone samples was performed. The results of the mineralogical analysis of urinary stones are shown in Table 1.

Table 1. Mineralogical composition of urinary stones using X-ray diffractometry and characteristics of patients. Weight percent (wt. \%) obtained from Rietveld calculations.

\begin{tabular}{|c|c|c|c|c|c|}
\hline Sample Number & Sample Type & Age & Gender & Minerals & wt. $\%$ \\
\hline MP-1 & Renal & 54 & Male & Whewellite & 100 \\
\hline MP-2 & Renal & 43 & Male & Whewellite & 100 \\
\hline MK-1 & Renal & 52 & Male & Whewellite & 100 \\
\hline MPo-1 & Renal & 55 & Male & Whewellite & 100 \\
\hline MPo-2 & Renal & 54 & Male & Whewellite & 100 \\
\hline MK-2 & Renal & 43 & Male & Whewellite & 100 \\
\hline MP-3 & Renal & 69 & Male & Whewellite & 100 \\
\hline MP-4 & Renal & 40 & Male & Uricite & 100 \\
\hline FP-1 & Renal & 63 & Female & Uricite & 100 \\
\hline MP-5 & Renal & 39 & Male & Uricite & 100 \\
\hline FK-1 & Renal & 56 & Female & Uricite & 100 \\
\hline MK-3 & Renal & 45 & Male & Uricite & 100 \\
\hline MK-4 & Renal & 58 & Male & Uricite & 100 \\
\hline MK-5 & Renal & 70 & Male & Uricite & 100 \\
\hline MB-3 & Bladder & 45 & Male & Uricite & 100 \\
\hline FK-2 & Renal & 24 & Female & L-Cystine & 100 \\
\hline FU & Ureter & 25 & Female & L-Cystine & 100 \\
\hline FP-2 & Renal & 29 & Female & Hydroxylapatite & 100 \\
\hline \multirow{2}{*}{ MPo-3 } & \multirow{2}{*}{ Renal } & \multirow{2}{*}{50} & \multirow{2}{*}{ Male } & Whewellite & 51.28 \\
\hline & & & & Uricite & 48.72 \\
\hline \multirow{2}{*}{ MPo-4 } & \multirow{2}{*}{ Renal } & \multirow{2}{*}{69} & \multirow{2}{*}{ Male } & Uricite & 78.51 \\
\hline & & & & Whewellite & 21.49 \\
\hline \multirow{2}{*}{ FPo-1 } & \multirow{2}{*}{ Renal } & \multirow{2}{*}{57} & \multirow{2}{*}{ Female } & Uricite & 91.88 \\
\hline & & & & Whewellite & 8.12 \\
\hline \multirow[b]{2}{*}{ MK-6 } & \multirow{2}{*}{ Renal } & \multirow{2}{*}{82} & \multirow{2}{*}{ Male } & Uricite & 82.05 \\
\hline & & & & Whewellite & 17.95 \\
\hline \multirow[b]{2}{*}{ MK-7 } & \multirow[b]{2}{*}{ Renal } & \multirow[b]{2}{*}{52} & \multirow[b]{2}{*}{ Male } & Uricite & 52.28 \\
\hline & & & & Whewellite & 47.72 \\
\hline \multirow[b]{2}{*}{ MP-6 } & \multirow[b]{2}{*}{ Renal } & \multirow[b]{2}{*}{47} & \multirow[b]{2}{*}{ Male } & Uricite & 82.03 \\
\hline & & & & Whewellite & 17.97 \\
\hline \multirow[b]{2}{*}{ MP-7 } & & & & Uricite & 83.71 \\
\hline & Renal & 48 & Male & Whewellite & 16.29 \\
\hline MPo-5 & Renal & 52 & Male & Whewellite & 100 \\
\hline & & & & Uricite & 74.54 \\
\hline МРo-6 & Renal & 43 & Male & Whewellite & 25.46 \\
\hline & & & & Whewellite & 76.90 \\
\hline FP-3 & Renal & 51 & Female & Uricite & 23.10 \\
\hline$M P Q$ & & & & Uricite & 73.20 \\
\hline $1 \mathrm{MIP-8}$ & Renal & 48 & Male & Whewellite & 26.80 \\
\hline & & & & Uricite & 75.88 \\
\hline FK-3 & Renal & 45 & Female & Whewellite & 24.12 \\
\hline
\end{tabular}


Table 1. Cont

\begin{tabular}{|c|c|c|c|c|c|}
\hline Sample Number & Sample Type & Age & Gender & Minerals & wt. $\%$ \\
\hline \multirow{2}{*}{ MP-9 } & \multirow{2}{*}{ Renal } & \multirow{2}{*}{27} & \multirow{2}{*}{ Male } & Whewellite & 76.30 \\
\hline & & & & Uricite & 23.70 \\
\hline \multirow{2}{*}{ FPo-2 } & \multirow{2}{*}{ Renal } & \multirow{2}{*}{37} & \multirow{2}{*}{ Female } & Uricite & 94.29 \\
\hline & & & & Whewellite & 5.71 \\
\hline \multirow{3}{*}{ MP-10 } & \multirow{3}{*}{ Renal } & \multirow{3}{*}{31} & \multirow{3}{*}{ Male } & Uricite & 60.40 \\
\hline & & & & Weddellite & 31.92 \\
\hline & & & & Whewellite & 7.68 \\
\hline \multirow{3}{*}{ MB-15 } & \multirow{3}{*}{ Bladder } & \multirow{3}{*}{54} & \multirow{3}{*}{ Male } & Uricite & 71.21 \\
\hline & & & & Whewellite & 20.92 \\
\hline & & & & Weddellite & 7.88 \\
\hline \multirow{2}{*}{ MPo-7 } & \multirow{2}{*}{ Renal } & \multirow{2}{*}{46} & \multirow{2}{*}{ Male } & Whewellite & 84.50 \\
\hline & & & & Weddellite & 15.50 \\
\hline \multirow{2}{*}{ MK-8 } & \multirow{2}{*}{ Renal } & \multirow{2}{*}{62} & \multirow{2}{*}{ Male } & Whewellite & 76.40 \\
\hline & & & & Weddellite & 18.40 \\
\hline \multirow{2}{*}{ FK-4 } & \multirow{2}{*}{ Renal } & \multirow{2}{*}{38} & \multirow{2}{*}{ Female } & Whewellite & 90.59 \\
\hline & & & & Weddellite & 9.41 \\
\hline \multirow{3}{*}{ MP-11 } & \multirow{3}{*}{ Renal } & \multirow{3}{*}{67} & \multirow{3}{*}{ Male } & Hydroxylapatite & 48.49 \\
\hline & & & & Whewellite & 32.41 \\
\hline & & & & Weddellite & 19.10 \\
\hline \multirow{3}{*}{ FP-4 } & \multirow{3}{*}{ Renal } & \multirow{3}{*}{65} & & Uricite & 49.07 \\
\hline & & & Female & Whewellite & 43.87 \\
\hline & & & & Calcium Urate & 7.06 \\
\hline
\end{tabular}

Rietveld refinement of XRD data of urinary stones in the Fars Province showed that whewellite and uricite were the most frequently occurring, while minerals such as cystine, hydroxyapatite, and also weddellite occurred less frequently as urinary stones (Table 1). Figures 1-4 also show some Rietveld refinement plots.

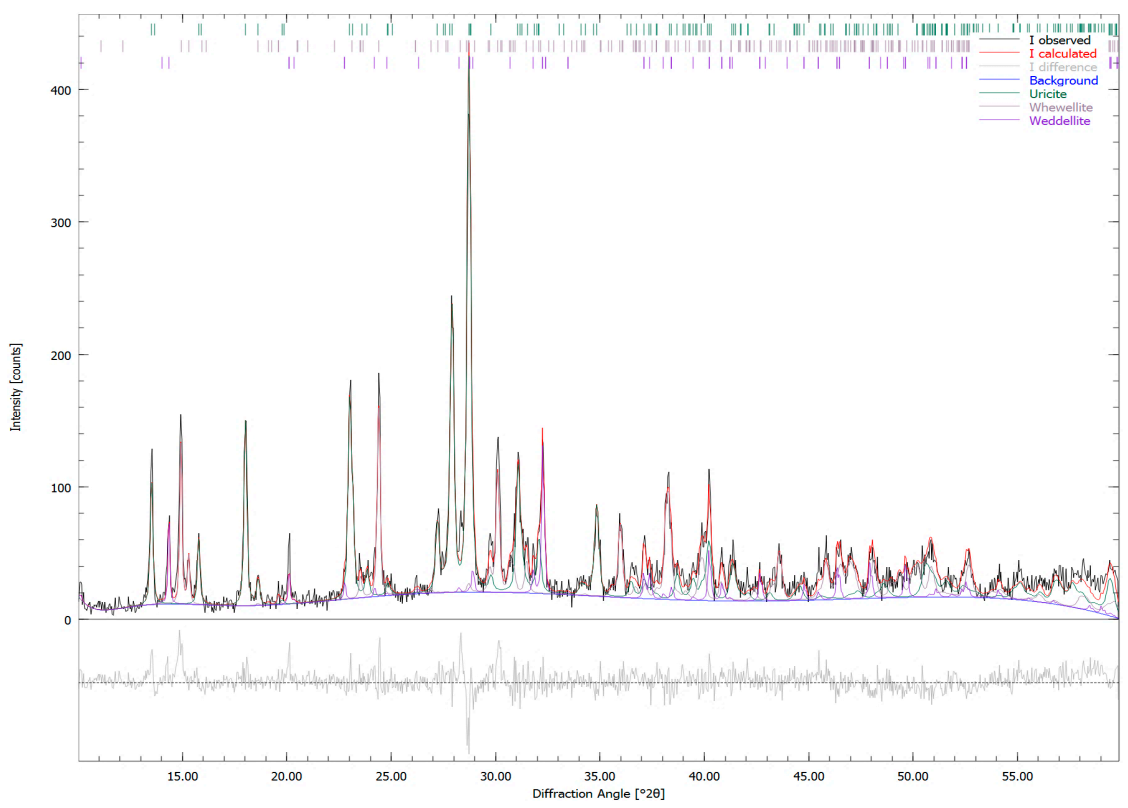

Figure 1. Rietveld graph of sample MB-15. Goodness-of-fit indicator as well as R-factors were: $X^{2}=1.56, R_{w p}=20.46 \%$, and $R_{\exp }=16.33 \%$. 


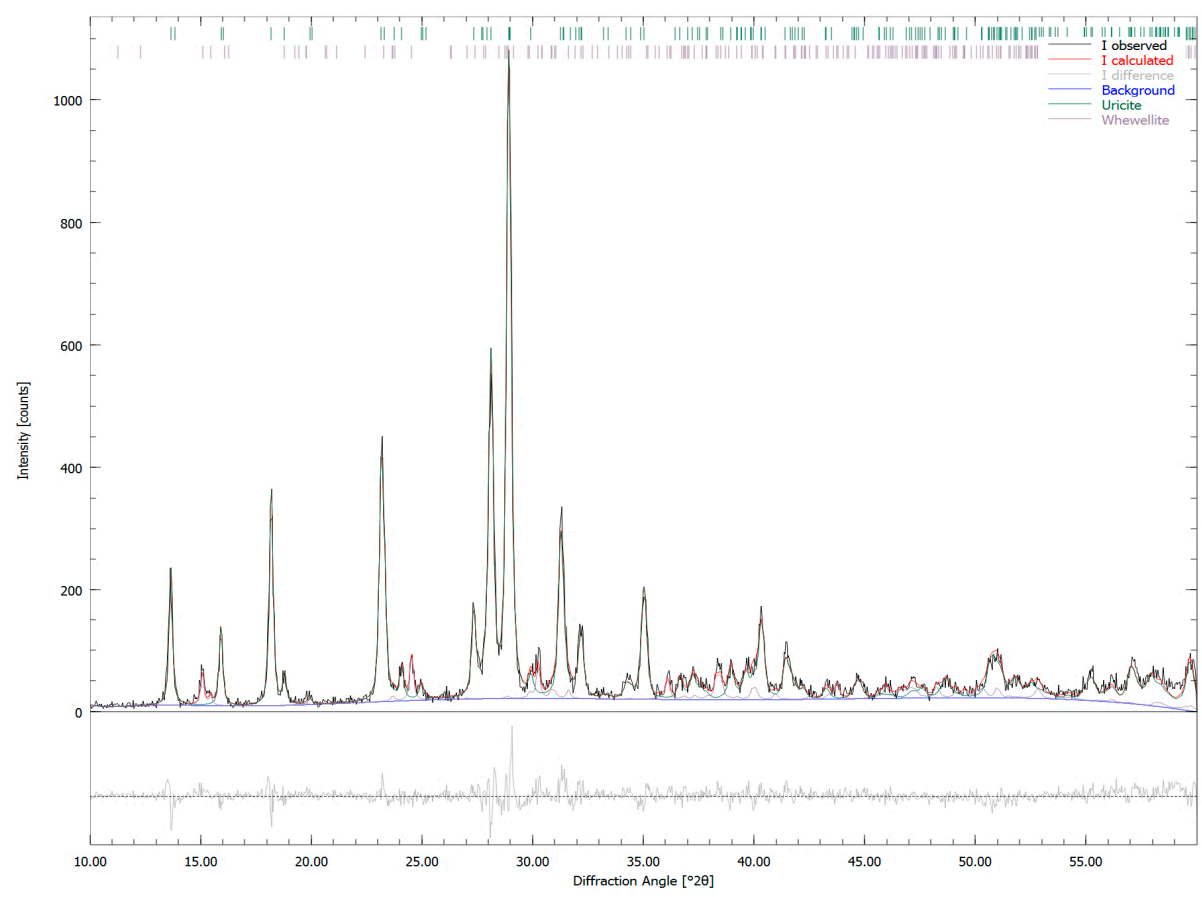

Figure 2. Rietveld graph of sample FPo-2. Goodness-of-fit indicator as well as R-factors were: $\mathrm{X}^{2}=1.88$, $R_{\mathrm{wp}}=17.95 \%$, and $R_{\exp }=13.70 \%$.

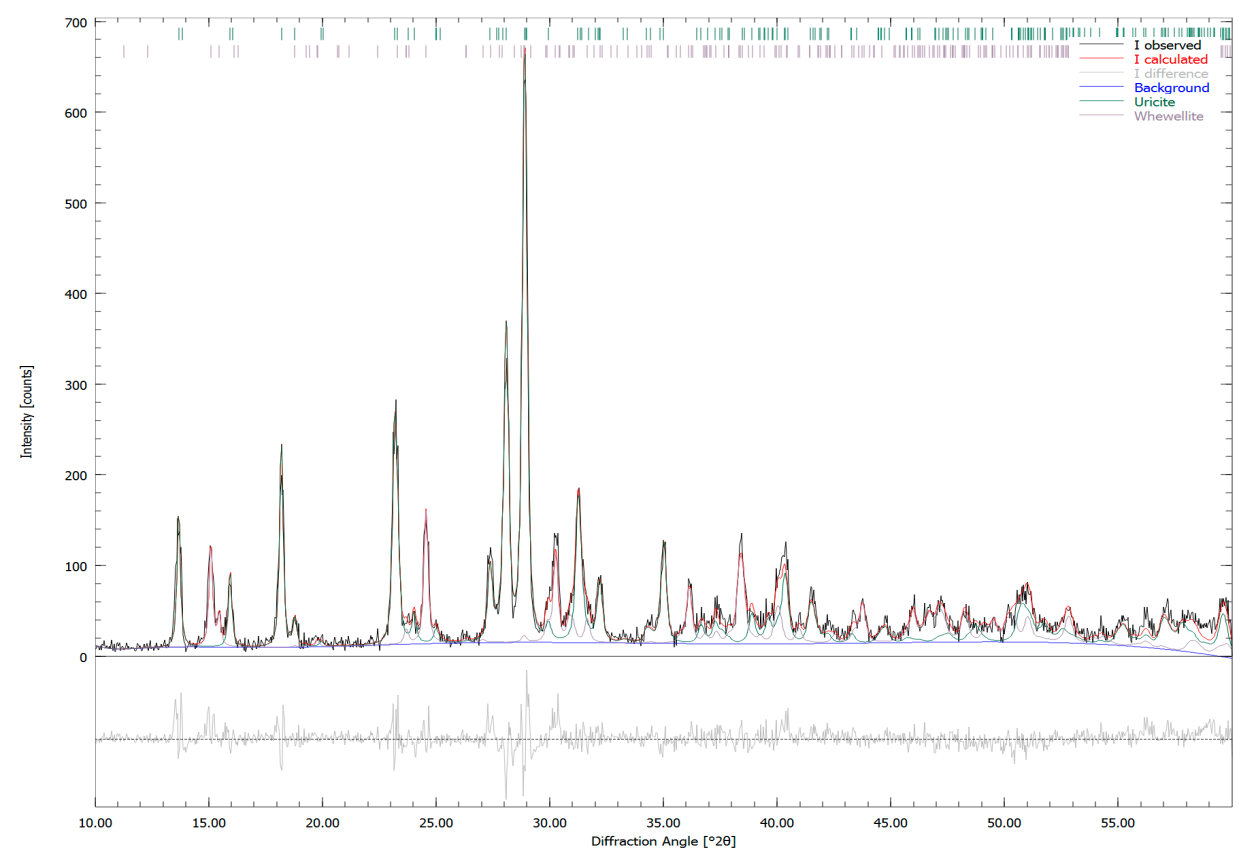

Figure 3. Rietveld graph of sample MP-6. Goodness-of-fit indicator as well as R-factors were: $X^{2}=1.99$, $\mathrm{R}_{\mathrm{wp}}=20.80 \%$, and $\mathrm{R}_{\exp }=14.71 \%$. 


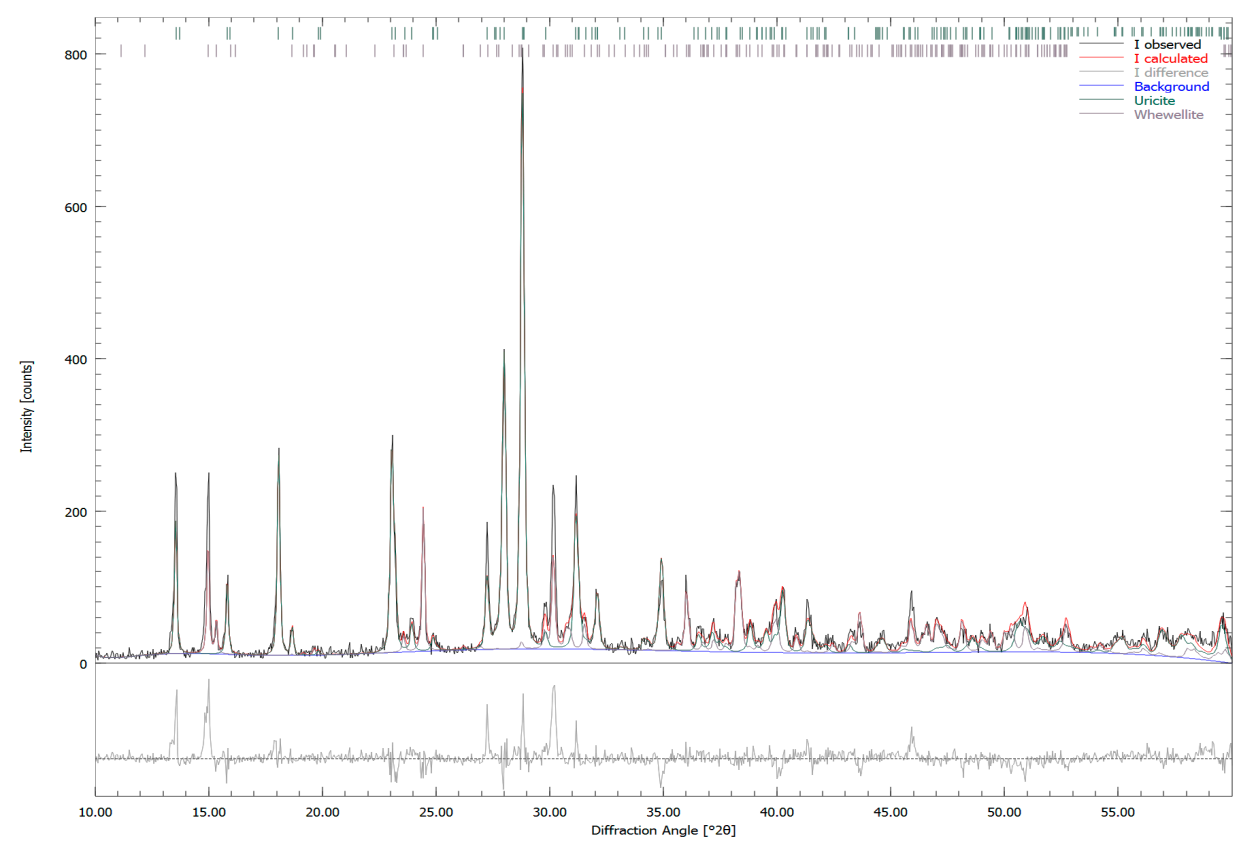

Figure 4. Rietveld graph of sample MK-6. Goodness-of-fit indicator as well as R-factors were: $X^{2}=2.06$, $\mathrm{R}_{\mathrm{wp}}=22.26 \%$, and $\mathrm{R}_{\exp }=15.48 \%$.

The hardness and color of urinary calculi are diversified. The whewellite calculi are hard and brown in color, and have sub-spherical to irregular shapes with rough surfaces $[9,20,24]$. Urinary apatite, consisting of hydroxyapatite, was usually soft with indefinite morphology, and could be rubbed to a fine powder with the finger. Their color ranged from near white to pale brown [12]. Uric acid stones are spherical with a smooth yellow-orange surface. Pure L-cystine stones are homogeneously composed of very small yellow spheroids [9]. The macroscopic views of two renal calculi and one bladder calculi with different mineral compositions, which were analyzed in our study, are shown in Figure 5.

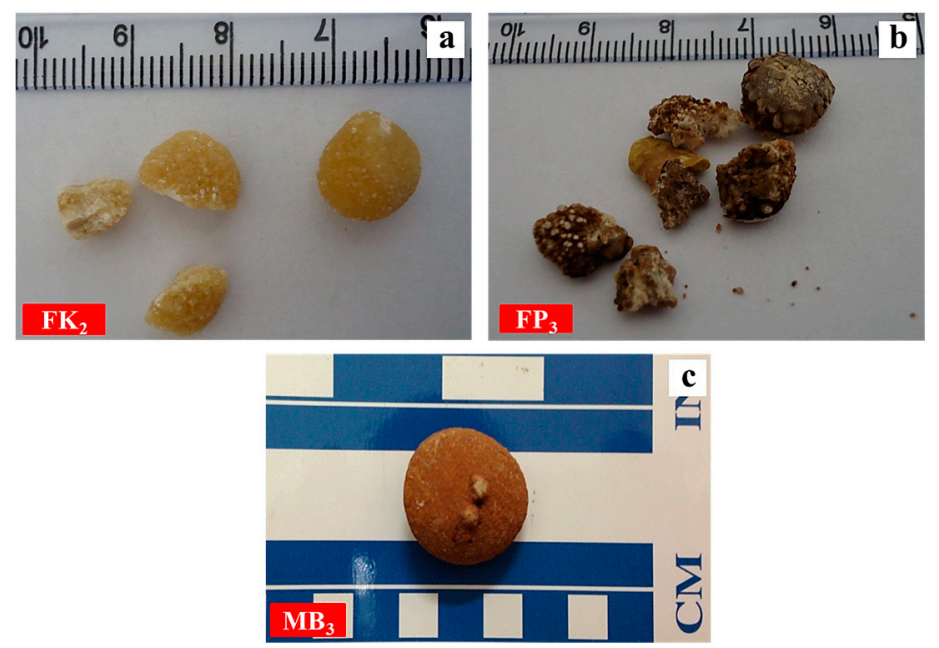

Figure 5. Macroscopic images of some the urinary stones analyzed in this study: renal stone with composition of cystine (a); renal stone with major constituents of whewellite and uricite in minor constituents (b); and bladder stone with uricite mineral (c).

Images taken from urinary stone samples by scanning electron microscopy (SEM) confirmed the X-ray diffraction results. Electron microscopy is a method for ultramicroscopic investigation of the fine structure of urinary stones and the possible presence of unknown components within the 
calculus $[25,26]$. SEM photos allow a morphological analysis of the stone surface and give information about the nature of crystalline compounds, shape of the crystal, internal structure, and some data about relations between crystals and matrix $[20,27]$. The SEM image showed that calcium oxalate minerals such as whewellite were characterized by a monoclinic system and platy-like morphology (Figure 6a) [28]. Figure 6b shows a hexagonal cystine crystal. Also, SEM image showed uric acid as a monoclinic prismatic crystal shape (Figure 6c).

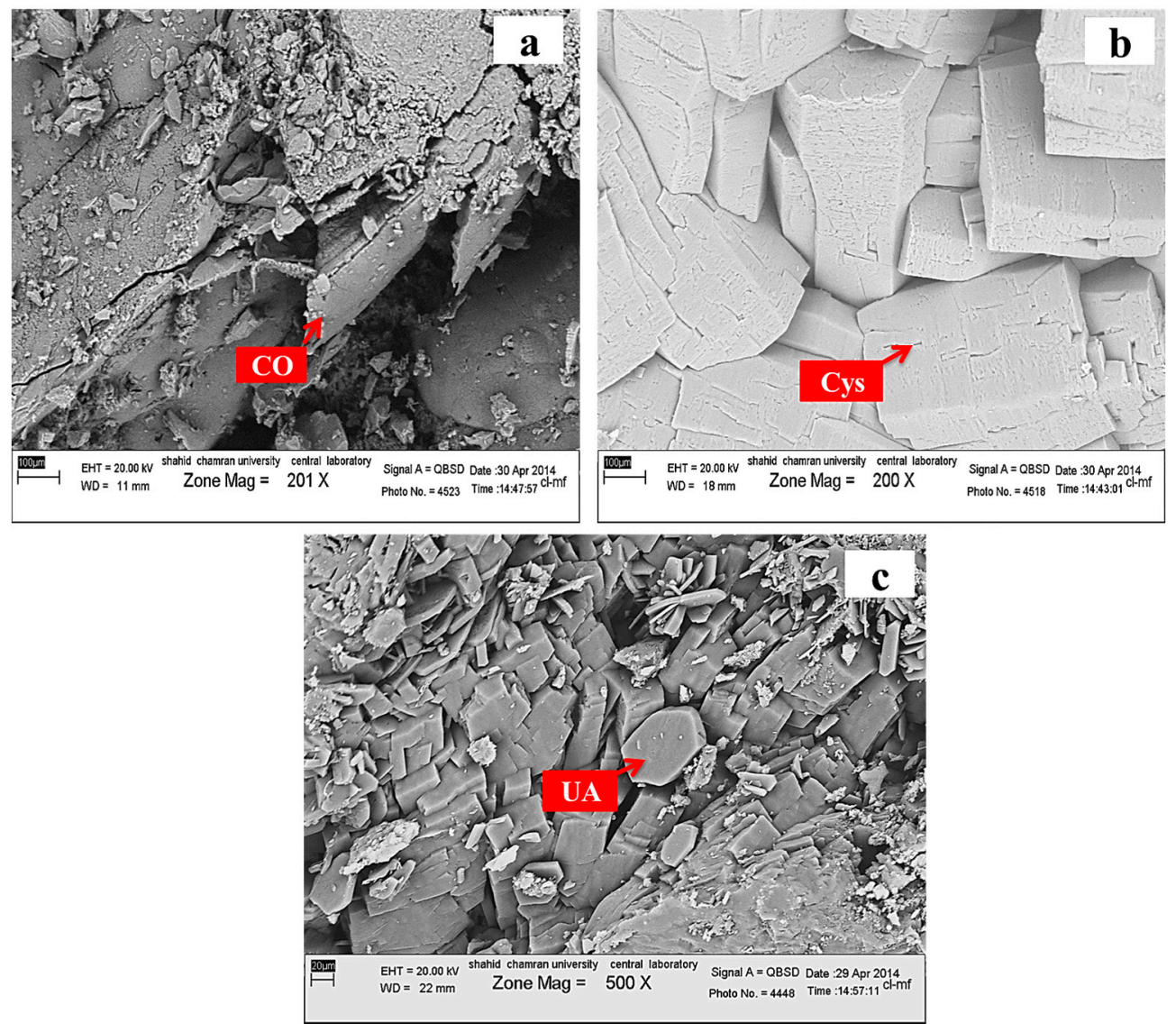

Figure 6. Platy-like calcium oxalate (CO) crystal (a); hexagonal cystine (Cys) crystal (b); and prismatic uric acid (UA) crystal (c) at scanning electron microscopy view.

The optical properties of different types of urinary stones were determined using a polarizing microscope (PM). In polarized light, it was possible to establish the presence of crystalline and amorphous materials that are helpful in identifying and differentiating these materials [20]. The results of thin-section microscopy of urinary stones using polarizing microscope showed mineralogical components of the urinary stones collected from Fars province patients. Urinary stones were classified into two mineral groups: calcium oxalate stones represented in whewellite minerals which were brownish to light brown in color. The present calcium oxalate stones showed radiating laminar texture with alternating pale brown to colorless whewellite laminae. The alternative laminea were concentrated around dark brown amorphous nuclei, and the stage of crystallization increased toward the stones' rim (Figure 7a-c) [27,29]. Therefore, the process of formation of urinary stones is probably similar to the crystallization processes of sedimentary grains such as pisoids and oncoids, which are initiated by precipitation of substances around one or more nuclei [20]. 

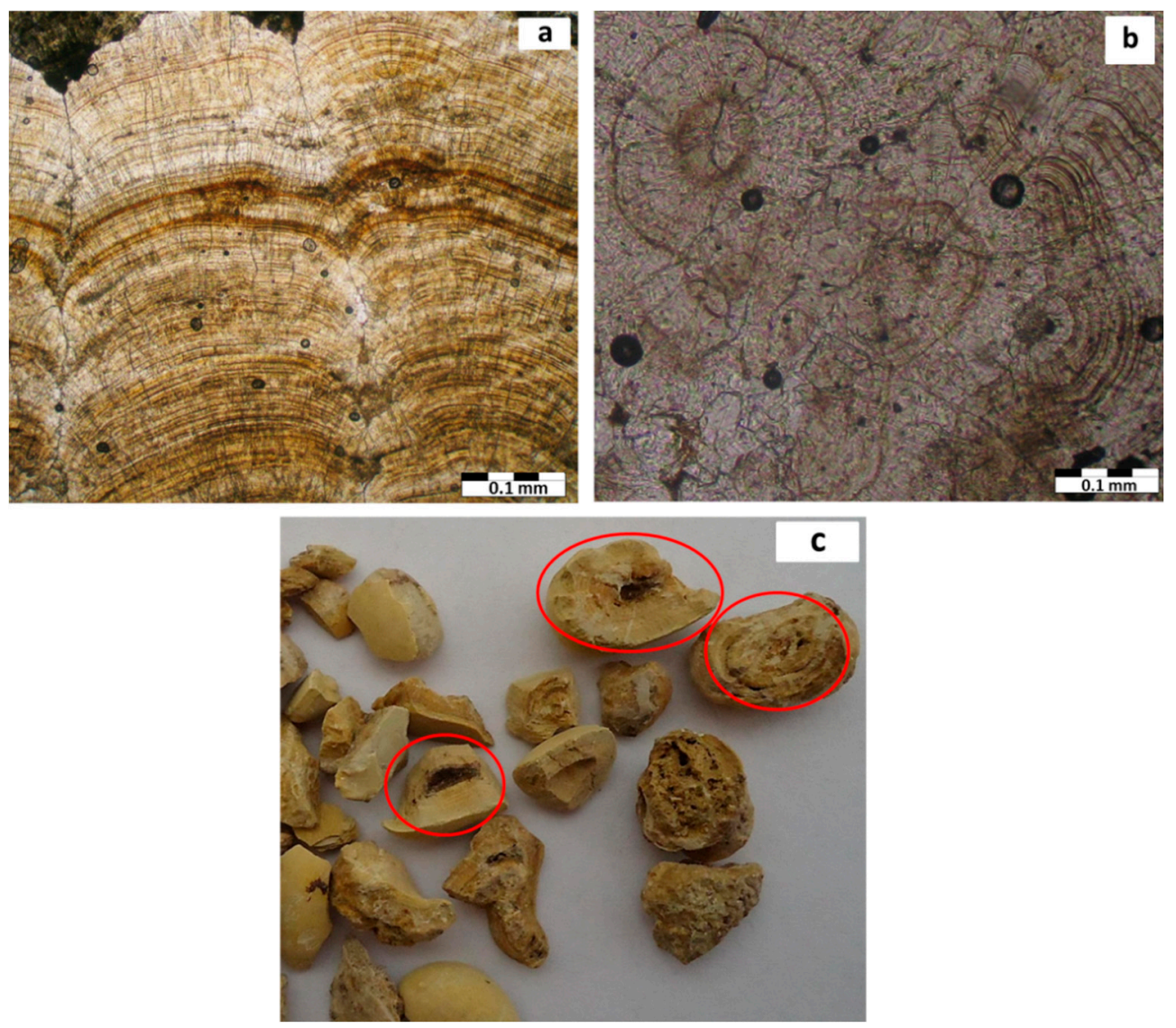

Figure 7. Polarizing microscopic images of calcium oxalate stones: (a) laminar texture in the whewellite mineral; (b) Concentric and radiate laminations of whewellite mineral of calcium oxalate stone around invisible nuclei; (c) Concentric laminations around a dark brown amorphous core in calcium oxalate stones.

Uric acid had fairly homogeneous microstructure. Concentric laminar rings could be rarely observed in uric acid samples. Figure 8 reveals concentric laminar layers and yellow color of uric acid stone. Radial texture of whewellite mineral with high content of iron (97 ppm in kidney stone samples) is shown in Figure 9 [30].The presence of Fe in calcium oxalate stones might result from the trapping of Fe ions at the crystal surface or in the crystal lattice [31].
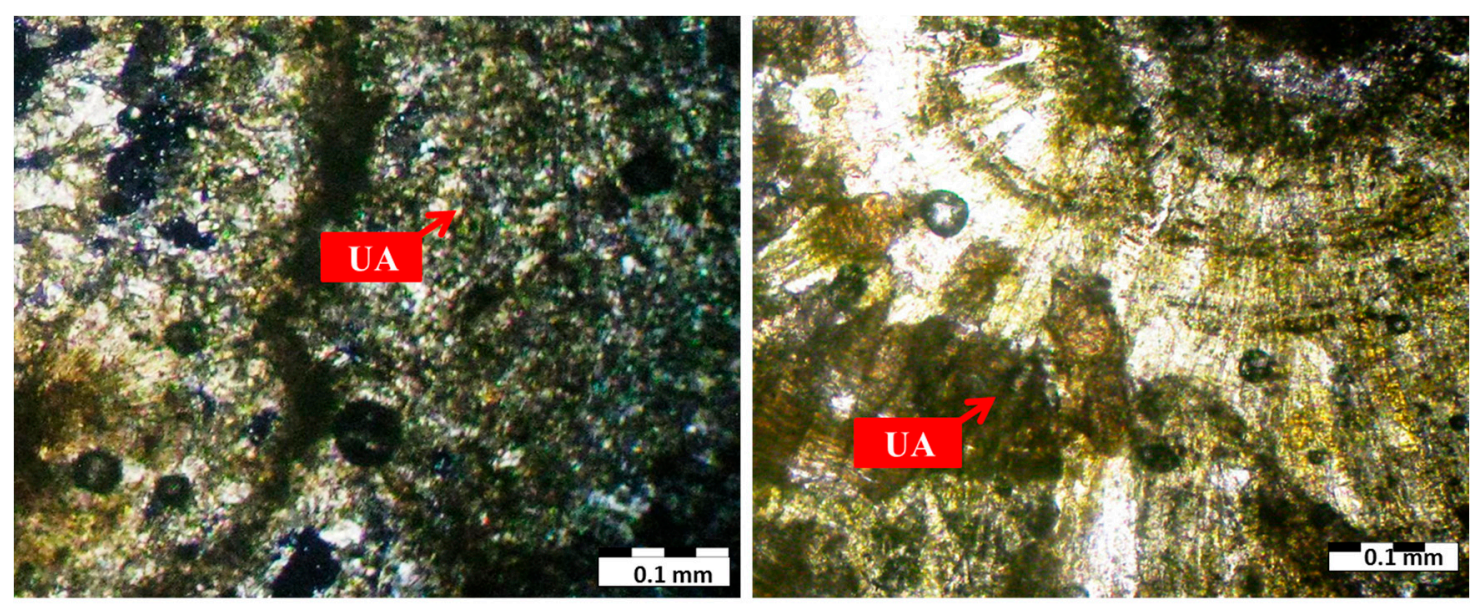

Figure 8. Polarizing microscopic images of uric acid stone (UA). 

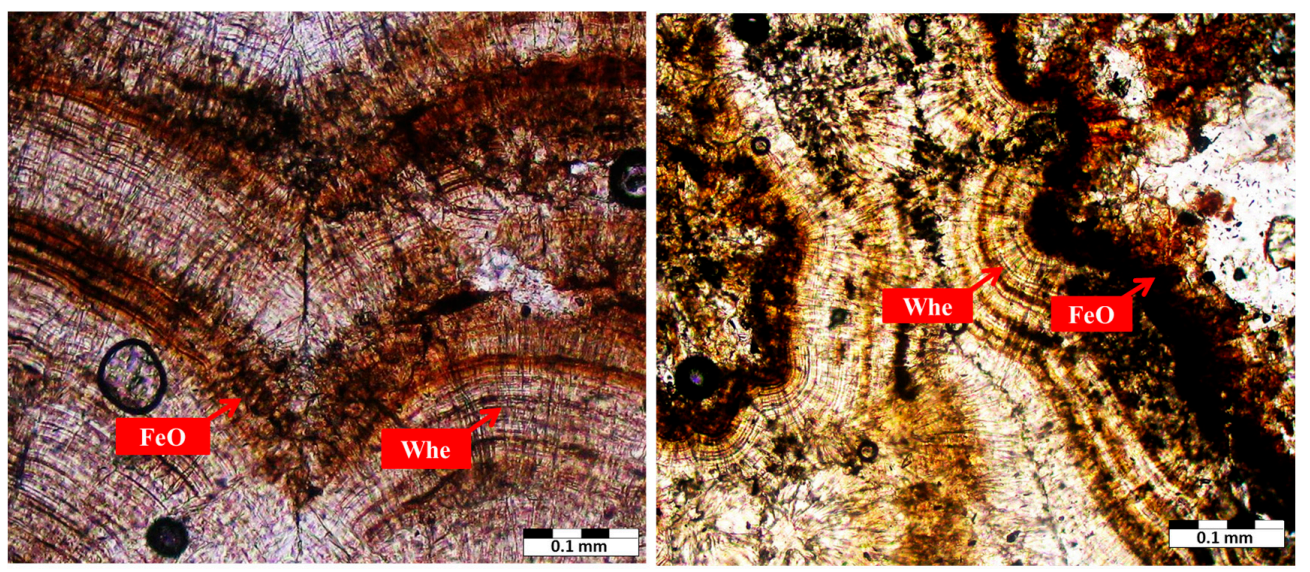

Figure 9. Radial texture of whewellite mineral (Whe) with high content of iron oxide (FeO).

When the acidity conditions of the urinary system were changed, uric acid and calcium oxalate were found together. Sometime stones were single large uricite crystals, while in other cases an entire uricite crystal was transformed into whewellite. Uricite mineral in the center of a kidney stone was transformed to whewellite mineral in its margins, as shown in Figure 10. Uric acid stones could result from either hyperuricosuria, acidic urine $\mathrm{pH}$, or both [32]. The primary cause of uric acid stones is a urinary $\mathrm{pH}$ below the $\mathrm{pKa}$ for uric acid (5.5). In other words, uric acid is 100 times more soluble at a $\mathrm{pH}>6$ compared to a $\mathrm{pH}<5.5[14,33]$. If the acidity of the urinary system is alkaline, acid urine will stay soluble and the conditions for calcium oxalate crystal deposition will be provided. These changes are related to environmental (food habits and water quality) and metabolic factors.

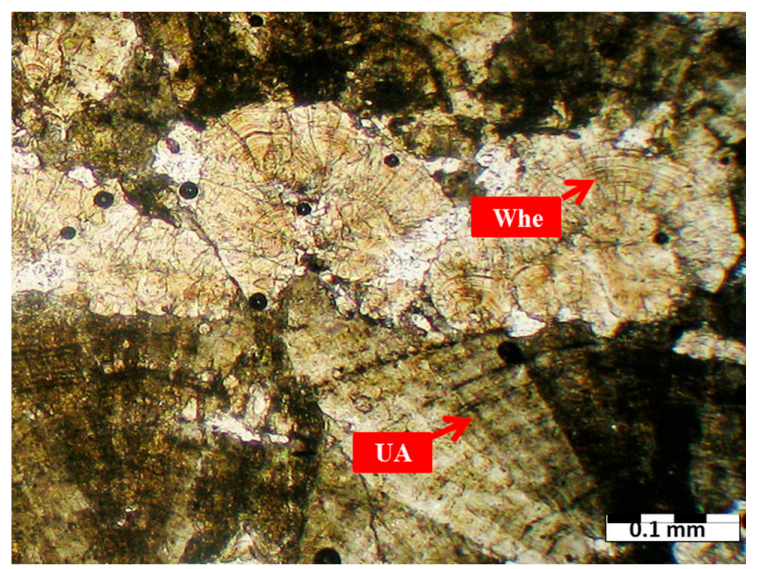

Figure 10. Polarizing microscopic image of mixed kidney stone: uric acid in center and whewellite in rim of stone.

Some minerals found in kidney stones are more familiar to rockhounds. Calcite and aragonite are rare as granular material intergrown in kidney stones [34]. Calcium carbonate (such as calcite and aragonite) is one of the most important biominerals and is abundant in both organisms and nature [35]. The processes of mineralization in the human body also produce pathological biominerals like kidney or urinary stones. Formation of crystals in pathological mineralizations follows the same principles as normal calcifications [3]. Calcium carbonate biominerals such as fibrous and rhombus aragonite were only found in some of the samples. The aragonite crystal was grown in eye fractures of amuric acid stone matrix (Figure 11a,b). The amorphous vaterite (Ca-carbonate, $6.2 \% \mathrm{~W}$ ) biomineral in calcium oxalate stone is also shown in Figure 12a. Also, quartz $\left(\mathrm{SiO}_{2}\right)$ was a very rare mineral in uroliths $[36,37]$ that was found in the calcium oxalate stone (Figure 12b). 

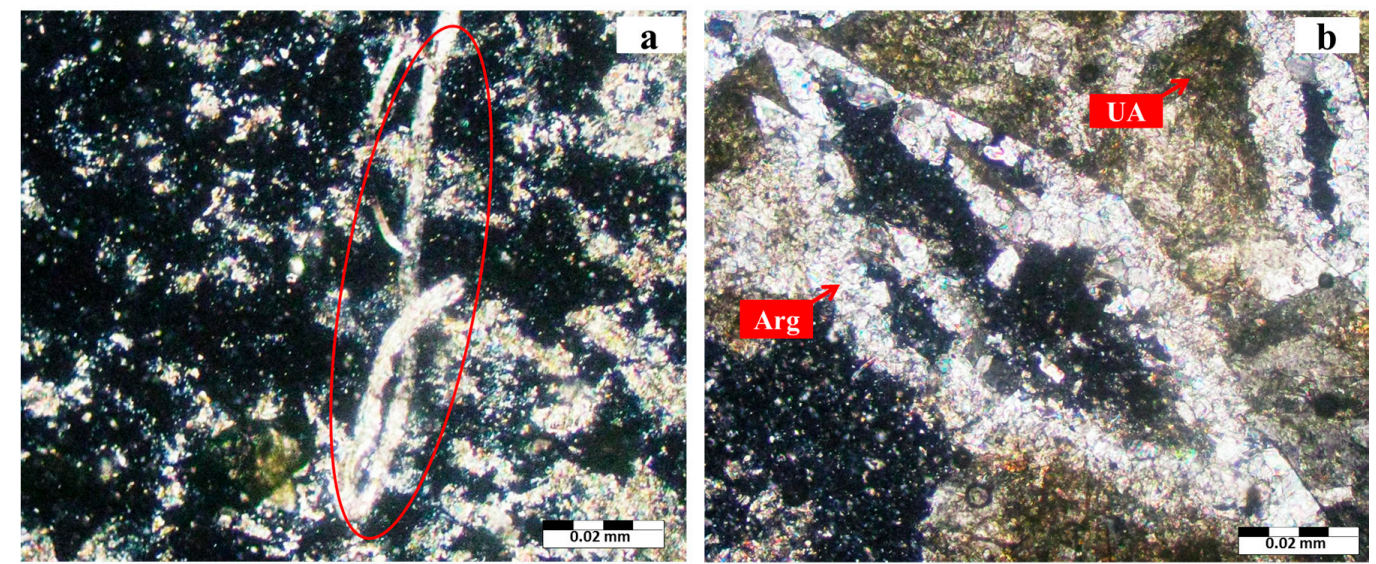

Figure 11. Polarizing microscopic images of biominerals in the uric acid stone: (a) fibrous aragonite (Arg); (b) rhombus aragonite.
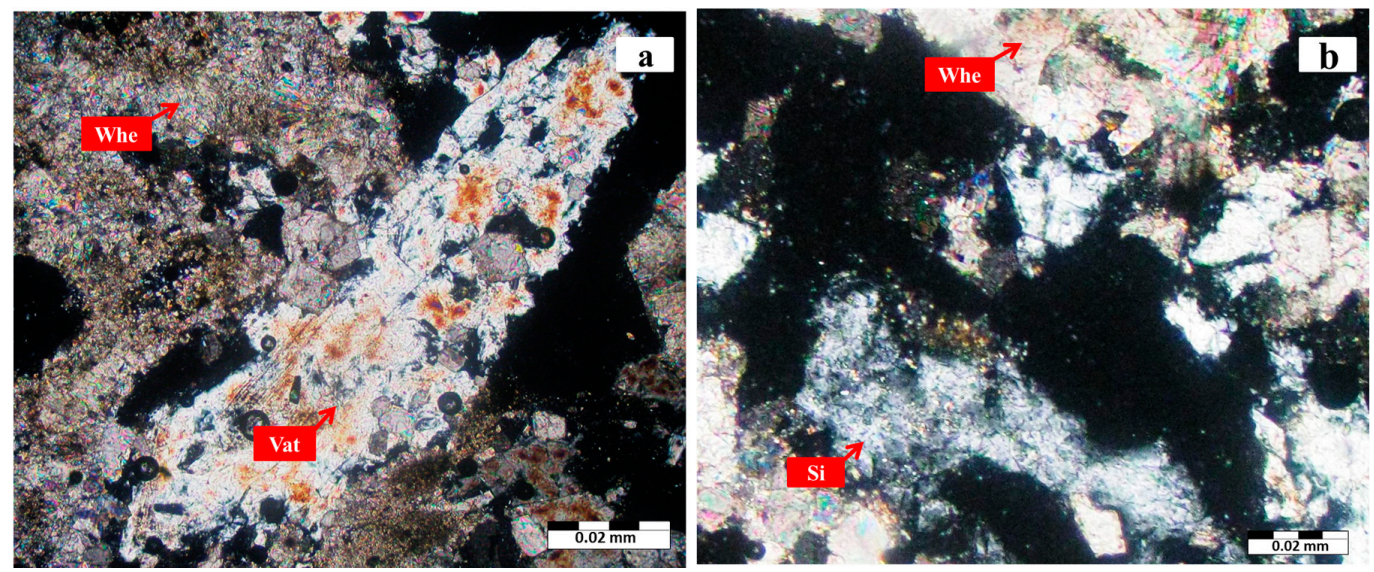

Figure 12. Polarizing microscopic images of amorphous vaterite (Vat) biomineral (a); and amorphous

Quartz (Si) in calcium oxalate stone (b) in sample MPo-3.

\subsection{Distribution of Urinary Stone by Age and Sex}

Urinary stone formation and the predominant chemical stone composition are age- and gender-dependent [38]. Incidence rates reported by age group consistently showed a rise-and-fall pattern as a population ages. Age at peak incidence was similar among Iran, Japan, and the United States: age at peak incidence was similar among these 3 countries, ranging from 40 to 49 years [39]. In addition, the prevalence of urinary stones disease is two to three times more common in males than in females, and the male-to-female ratio was 1.15:1 in Iran [40].

Due to the small number of analyzed samples $(n=39)$, which can be considered a limitation in this research, all the conclusions made in the section are mentioned as tentative. $64.1 \%$ of patients were male and $35.9 \%$ were female. Table 2 displays influence of age and sex of patients on the formation and type of urinary stones. According to the results of the mineralogical analysis, the samples are classified into five mineral groups [30].

The prevalence of urinary stone was higher among patients aged 40-60 years old. Significant increase in uric acid $(10.26 \%)$, calcium oxalate $(23.1 \%)$ and mixed stones calcium oxalate and uric acid (25.64\%) frequency in ages ranging from 40 to 60 years showed an increased occurrence in the group of minerals with increasing age. Baker et al. found that the peak age for the development of calcium oxalate stones was between 50 and 60 years [41]. 
Table 2. Distribution of mineral groups according to age and sex of patients.

\begin{tabular}{|c|c|c|c|c|c|c|c|c|c|c|}
\hline \multirow{2}{*}{$\begin{array}{l}\text { Age } \\
\text { Group }\end{array}$} & \multicolumn{2}{|c|}{ Calcium Oxalate } & \multicolumn{2}{|c|}{ Uric Acid } & \multicolumn{2}{|c|}{ Cystine } & \multicolumn{2}{|c|}{ Calcium Phosphate } & \multicolumn{2}{|c|}{ Mixed Stone } \\
\hline & Female & Male & Female & Male & Female & Male & Female & Male & Female & Male \\
\hline$<40$ & 1 & - & - & 1 & 2 & - & 1 & - & 1 & 2 \\
\hline $40-50$ & - & 3 & - & 3 & - & - & - & - & 1 & 4 \\
\hline $50-60$ & 4 & 2 & 1 & - & - & - & - & - & 1 & 4 \\
\hline$>60$ & - & 2 & 1 & 1 & - & - & - & 1 & 1 & 2 \\
\hline
\end{tabular}

Urinary stones were more common in male patients in each range of ages except in patients aged below 40 years old, in whom the prevalence of urinary stone was more common in female compared to male patients. This may be due to a higher incidence of urinary tract infection as one of the risk factors of urinary stone in this sexually active group of patients [42]. Calcium-containing calculi and uric acid are predominant in males over females. Daudon et al. showed a male predominance for calcium oxalate and uric acid. Cystine stones, formed by patients with cystinuria, account for only a small percentage of all urinary stones ( 1 of 39 urinary stone samples). The higher peak in younger ages is in accordance with the first stone event, which typically occurs in the 2nd decade of life, whereas the lower frequency at older ages may be a result of preventive measures [38,43].

\section{Conclusions}

The importance of mineralogy in the field of medicine lies in the application of mineralogical methods to study pathological mineral deposits in the human body. Therefore, this study underestimated real urinary disease prevalence, but for the aim of the study it was only necessary to verify a difference in the composition of urolithiasis and also verify the impact of age and sex on the distribution of the pathology in the Fars Province. The application of XRD, SEM and polarizing microscopic (PM) techniques enabled us to explain the detailed characterization of mineralogical composition of the urinary stones. The results of QXRD analysis indicated that the urinary stones had different mineralogical compositions. Uricite and whewellite minerals were the most frequently occurring. Minerals such as cystine, hydroxyapatite and weddellite occurred less frequently as urinary stones. SEM analysis results confirmed the XRD analyses. Platy-like/monoclinic whewellite, prismatic/monoclinic uric acid and hexagonal cystine crystals were revealed by SEM. Urinary stones studied by PM revealed biominerals such as whewellite, uricite and calcium carbonate. These minerals showed that formation of crystals in pathological mineralization follows the same principles as normal calcifications. Moreover, quartz was a very rare mineral component in uroliths, so more detailed investigation (such as Energy dispersive $\mathrm{X}$-ray analysis and quantitative analysis by $\mathrm{XRD}$ ) of the nature and origin of $\mathrm{SiO}_{2}$ in the sample will give a greater understanding of the formation mechanism.

In addition, we found a relationship between age, sex and frequency of urinary stones according to their mineralogical composition. The highest incidence of urinary stones was observed in the 40-60 age group. Comparison of data related to the age group and mineralogy of urinary stones revealed a possible relationship between the age group and increase in frequency of calcium oxalate and uric acid minerals. Calcium oxalate and uric acid stones are more frequent in men than women. Thus, various forms of minerals present in the urinary stones can be helpful in identification of possible environmental (food habits and water quality) and metabolic factors.

Acknowledgments: This research was supported by Shiraz University's "Medical Geology Research Centre", to whom the authors are indebted. We would also like to extend our thanks to the Shiraz University research committee for logistic assistance. Also, detailed comments of Editor-in-Chief and the anonymous reviewers significantly improved the manuscript.

Author Contributions: Behnam Keshavarzi and Farid Moore conceived and designed the experiments; Dariush Irani and Mehrdad Salari performed the experiments; Nasrin Yavar Ashayeri collected the samples; Alireza Zarasvandi analyzed the samples; Behnam Keshavarzi and Nasrin Yavar Ashayeri interpreted data; Sina Asadi study interpretation of thin sections and Rietveld refinement of XRD data; Nasrin Yavar Ashayeri wrote the paper. 
Conflicts of Interest: The authors declare no conflict of interest.

\section{References}

1. Sahai, N. Modeling apatite nucleation in the human body and in the geochemical environment. Am. J. Sci. 2005, 305, 661-672. [CrossRef]

2. Bazin, D.; Daudon, M.; Combes, C.; Rey, C. Characterization and some physicochemical aspects of pathological microcalcifications. Chem. Rev. 2012, 112, 5092-5120. [CrossRef] [PubMed]

3. Giannossi, M.L.; Summa, V. A Review of Pathological Biomineral Analysis Techniques and Classification Schemes; INTECH Open Access Publisher: Rijeka, Croatia, 2012.

4. Selvaraju, R.; Raja, A.; Thiruppathi, G. FT-IR spectroscopic, thermal analysis of human urinary stones and their characterization. Spectrochim. Acta Part A Mol. Biomol. Spectrosc. 2015, 137, 1397-1402. [CrossRef] [PubMed]

5. Kuta, J.; Smetanová, S.; Benová, D.; Kořistková, T.; Machát, J. Urinary stones as a novel matrix for human biomonitoring of toxic and essential elements. Environ. Geochem. Health 2016, 38, 133-143. [CrossRef] [PubMed]

6. Schubert, G. Stone analysis. Urol. Res. 2006, 34, 146-150. [CrossRef] [PubMed]

7. Macfarlane, M.T. Urology, 2nd ed.; William \& Wilkins: Baltimore, MD, USA, 1995.

8. Singh, V.K.; Rai, A.K.; Rai, P.K.; Jindal, P.K. Cross-sectional study of kidney stones by laser-induced breakdown spectroscopy. Lasers Med. Sci. 2009, 24, 749-759. [CrossRef] [PubMed]

9. Master, V.A.; Meng, M.M.; Stoller, M.L. Urinary Stone Disease: The Practical Guide to Medical and Surgical Management; Humana Press: Totowa, NJ, USA, 2007.

10. Giannossi, M.L.; Summa, V.; Mongelli, G. Trace element investigations in urinary stones: A preliminary pilot case in Basilicata (Southern Italy). J. Trace Elem. Med. Biol. 2013, 27, 91-97. [CrossRef] [PubMed]

11. Mandel, I.; Mandel, N. Structure and compositional analysis of kidney stones. In Urinary Stone Disease; Humana Press: Totowa, NJ, USA, 2007; pp. 69-81.

12. Gray, D.; Laing, M.; Nel, F.; Naudé, J.H. The Composition of Urinary Calculi Collected in the Durban Area. S. Afr. Med. J. 1982, 61, 121-125. [PubMed]

13. Scales, C.D.; Smith, A.C.; Hanley, J.M.; Saigal, C.S.; Urologic Diseases in America Project. Urologic Diseases in America Project. Prevalence of kidney stones in the United States. Eur. Urol. 2012, 62, 160-165. [CrossRef] [PubMed]

14. Pietrow, P.K.; Karellas, M.K. Medical management of common urinary calculi. S. Afr. Fam. Pract. 2007, 49, $44-48$.

15. Golub, E.E. Biomineralization and matrix vesicles in biology and pathology. In Seminars in Immunopathology; Springer: New York, NY, USA, 2011; Volume 33, pp. 409-417.

16. Golovanova, O.A.; Frank-Kamenetskaya, O.V.; Punin, Y.O. Specific features of pathogenic mineral formation in the human body. Russ. J. Gen. Chem. 2011, 81, 1392-1406. [CrossRef]

17. Cheng, C.L.; Chang, H.H.; Huang, P.J.; Chu, Y.T.; Lin, S.Y. Composition and distribution of elements and ultrastructural topography of a human cardiac calculus. Biol. Trace Elem. Res. 2013, 152, 143-151. [CrossRef] [PubMed]

18. Giannossi, M.L.; Summa, V. An observation on the composition of urinary calculi: Environmental influence. In Medical Geochemistry; Springer Netherlands: Dordrecht, The Netherlands, 2013; pp. 67-90.

19. Raman, C.V.; Krishnan, K.S. A new type of secondary radiation. Nature 1928, 121, 501-502. [CrossRef]

20. Abboud, I.A. Mineralogy and chemistry of urinary stones: Patients from North Jordan. Environ. Geochem. Health 2008, 30, 445-463. [CrossRef] [PubMed]

21. Doebelin, N.; Kleeberg, R. Profex: A graphical user interface for the Rietveld refinement program BGMN. J. Appl. Crystallogr. 2015, 48, 1573-1580. [CrossRef] [PubMed]

22. Bergmann, J.; Friedel, P.; Kleeberg, R. BGMN-A new fundamental parameters based Rietveld program for laboratory X-ray sources, its use in quantitative analysis and structure investigations. CPD Newsl. 1998, 20, $5-8$.

23. Mukherjee, A.K. Human kidney stone analysis using X-ray powder diffraction. J. Indian Inst. Sci. 2014, 94, $35-44$. 
24. Shamema, A.A.; Arul, K.T.; Kumar, R.S.; Kalkura, S.N. Physicochemical analysis of urinary stones from Dharmapuri district. Spectrochim. Acta Part A Mol. Biomol. Spectrosc. 2015, 134, 442-448. [CrossRef] [PubMed]

25. Hesse, A.; Hicking, W.; Bach, D.; Vahlensieck, W. Characterisation of urinary crystals and thin polished sections of urinary calculi by means of an optical microscopic and scanning electron microscopic arrangement. Urol. Int. 1981, 36, 281-291. [CrossRef] [PubMed]

26. Hyacinth, P.; Rajamohanan, K.; Marckar, F.Y.; Koshy, P.; Krishnamurthy, S. A study of the ultrastructure of urinary calculi by scanning electron microscopy. Urol. Res. 1984, 12, 227-230. [CrossRef] [PubMed]

27. Afaj, A.H.; Sultan, M.A. Mineralogical composition of the urinary stones from different provinces in Iraq. Sci. World J. 2005, 5, 24-38. [CrossRef] [PubMed]

28. Hesse, A.; Tiselius, H.G.; Siener, R.; Hoppe, B. Urinary Stones: Diagnosis, Treatment, and Prevention of Recurrence; 3rd revised and enlarged ed.; S. Karger: Basel, Switzerland, 2009; p. 232.

29. Zarasvandi, A.; Carranza, E.J.; Heidari, M.; Mousapour, E. Environmental factors of urinary stones mineralogy, Khouzestan Province, Iran. J. Afr. Earth Sci. 2014, 97, 368-376. [CrossRef]

30. Keshavarzi, B.; Yavarashayeri, N.; Irani, D.; Moore, F.; Zarasvandi, A.; Salari, M. Trace elements in urinary stones: A preliminary investigation in Fars province, Iran. Environ. Geochem. Health. 2015, 37, 377-389. [CrossRef] [PubMed]

31. Bazin, D.; Chevallier, P.; Matzen, G.; Jungers, P.; Daudon, M. Heavy elements in urinary stones. Urol. Res. 2007, 35, 179-184. [CrossRef] [PubMed]

32. Moe, O.W. Kidney stones: Pathophysiology and medical management. Lancet 2006, 367, 333-344. [CrossRef]

33. Robertson, W.G. Urinary tract stones. In Medical Therapy in Urology; Springer: London, UK, 2010; pp. 147-162.

34. Gibson, R.I. Descriptive human pathological mineralogy. Am. Mineral. 1974, 59, 1177-1182.

35. Ma, M.G.; Sun, R.C. Biomineralization and Biomimetic Synthesis of Biomineral and Nanomaterials; INTECH Open Access Publisher: Rijeka, Croatia, 2011.

36. Potapov, S.S.; Parshina, N.V.; Moroz, T.N.; Lyutoev, V.P. Presented at the International Workshop “Quartz. Silica”, Syktyvkar, Russia, 2004. (In Russian)

37. Pal'chik, N.A.; Moroz, T.N.; Maksimova, N.V.; Dar'in, A.V. Mineral and microelement compositions of urinary stones. Russ. J. Inorg. Chem. 2006, 51, 1098-1105. [CrossRef]

38. Knoll, T. Epidemiology, pathogenesis, and pathophysiology of urolithiasis. Eur. Urol. Suppl. 2010, 9, 802-806. [CrossRef]

39. Romero, V.; Akpinar, H.; Assimos, D.G. Kidney stones: A global picture of prevalence, incidence, and associated risk factors. Rev. Urol. 2010, 12, e86-e96. [PubMed]

40. Pourmand, G.; Pourmand, B. Epidemiology of Stone Disease in Iran. In Urolithiasis; Springer: London, UK, 2012; pp. 85-87.

41. Baker, P.W.; Coyle, P.; Bais, R.; Rofe, A.M. Influence of season, age, and sex on renal stone formation in South Australia. Med. J. Aust. 1993, 159, 390-392. [PubMed]

42. Hosseini, M.M.; Eshraghian, A.; Dehghanian, I.; Irani, D.; Amini, M. Metabolic abnormalities in patients with nephrolithiasis: Comparison of first-episode with recurrent cases in Southern Iran. Int. Urol. Nephrol. 2010, 42, 127-131. [CrossRef] [PubMed]

43. Daudon, M.; Doré, J.C.; Jungers, P.; Lacour, B. Changes in stone composition according to age and gender of patients: A multivariate epidemiological approach. Urol. Res. 2004, 32, 241-247. [CrossRef] [PubMed]

(C) 2016 by the authors; licensee MDPI, Basel, Switzerland. This article is an open access article distributed under the terms and conditions of the Creative Commons Attribution (CC-BY) license (http://creativecommons.org/licenses/by/4.0/). 